\title{
Patient Satisfaction Survey at a Tertiary Care Speciality Hospital
}

\author{
${ }^{1}$ Neeraj Garg, ${ }^{2}$ Shakti Kumar Gupta, ${ }^{3} \mathrm{R}$ Mahesh
}

\begin{abstract}
Introduction: Patient satisfaction is one of the most important parameters of quality. The measurement of patient satisfaction is an important tool for research, administration, and planning. Client satisfaction is a crucial index for determining the quality services and the way in which they are provided by medical staff. The patient satisfaction is of paramount importance in ensuring better quality on the way to total quality management. Patient satisfaction survey are important from the view of improvement of quality of services and to attain the maximum satisfaction of the in-patients.
\end{abstract}

Aims and objectives: The aim of the study is to assess the level of satisfaction of in-patients at Tertiary care speciality hospital and to find out the causes for dissatisfaction. The objectives set were, to study the level of satisfaction of in-patients in private and General wards at Tertiary care speciality hospital and to find the causes for dissatisfaction, if any and suggest remedial measures.

Methodology: A questionnaire based study where views of inpatient were taken regarding various clinical and support services. The data were collected from different patient care areas over a period of 2 months, and analyzed to determine the biggest dissatisfying factors among the patients.

Observations: More than $88 \%$ of the patients have rated the services as Excellent/Good. The areas where the satisfaction level is low is the cleanliness specially in the toilets and the quality of food served to the patients. As far as clinical care is concerned $95 \%$ of the patients are satisfied with the level and expertise of professional care but suggested for development of soft skills in doctors and paramedics.

Conclusion: The study suggests that a majority of in-patients are highly satisfied with the services of the Hospital. The study recommends for the need to develop soft skills among Doctor and paramedics and to improve upon the level of cleanliness and quality of dietary services.

\footnotetext{
${ }^{1}$ Lieutenant Colonel, ${ }^{2}$ Medical Superintendent

${ }^{3}$ Assistant Professor

${ }^{1} \mathrm{MOHS}$, Army Hospital (Research and Referral), Delhi Cantt New Delhi, India

${ }^{2} \mathrm{Dr}$ RP Centre for Ophthalmic Sciences, All India Institute of Medical Sciences, New Delhi, India

${ }^{3}$ Department of Hospital Administration, All India Institute of Medical Sciences, New Delhi, India
}

Corresponding Author: Neeraj Garg, Lieutenant Colonel MOHS, Army Hospital (Research and Referral), Delhi Cantt New Delhi, India, e-mail: drneerajgarg1974@gmail.com
Keywords: Patient satisfaction, Soft skills, Cleanliness in toilets, Dietary services.

How to cite this article: Garg N, Gupta SK, Mahesh R. Patient Satisfaction Survey at a Tertiary Care Speciality Hospital. Int J Res Foundation Hosp Healthc Adm 2014;2(2):79-83.

Source of support: Nil

\section{Conflict of interest: None}

\section{INTRODUCTION}

Patient satisfaction is one of the most important parameters of quality. The measurement of patient satisfaction is an important tool for research, administration, and planning. ${ }^{1}$ Client satisfaction is a crucial index for determining the quality services and the way in which they are provided by medical staff. Satisfaction with the physicians, nurses, equipment, housekeeping, billing, and food services were the main determinants of overall satisfaction in hospitalized patients. ${ }^{2}$ The patient satisfaction is of paramount importance in ensuring better quality on the way to total quality management, because the patient (customer) is the one who decides the quality, who accepts the goods/services, who makes the other to accept it, who decides your market strategies, who gives correct feedback about the performance of the hospital, and makes success the program of total quality management. ${ }^{3}$ Patient satisfactions is an indicator of how the patient has perceived the other qualitative aspects of care and can be used as a proxy measure of those aspects. ${ }^{4}$ Patient satisfaction is a pre-requisite for achieving the goals of healthcare as it influences the patient's decision to follow prescribed treatments and seek professional healthcare in the future. Patients are capable of assessing the quality of care, they receive as they pay attention to all components of care - the science of medicine, the art of care, and the amenities of care. ${ }^{5}$ Hospital satisfaction questionnaire asked respondents general questions relating to reception/administration, hospital cleanliness, signage, hospital food, etc.

Patient satisfaction survey are important from the view of improvement of quality of services and to attain the maximum satisfaction of the in-patients.

A cross-sectional study of satisfaction of in-patients in a Private Medical College Hospital in AP by Rajagopal Rao Kodali, P Sita Ramacharyulu ${ }^{6}$ showed that the satisfaction of in-patients expressed by majority was good followed by fair, 
bad, very good, and very bad. The satisfaction expressed was more with nursing services followed by doctors and billing and least with housekeeping.

The study recommends that the doctors and nurses should be motivated by conducting CME programs, seminars, and sensitization workshops periodically. Medical and nursing audits can be introduced to improve the quality of medical care and to reduce the cost to the patient. Housekeeping staff should be posted in all the wards round the clock in sufficient numbers and maintain the neatness of the wards by using disinfectants and their work should be supervised from time to time.

Examining the relationship between patient-centered care (PCC) and outcomes by Poochikian-Sarkissian S, Sidani $\mathrm{S}$, Ferguson-Pare M, Doran $\mathrm{D}^{7}$ to examine the extent to which staff nurses provided PCC, as perceived by staff nurses and patients, and to explore the relationships between implementation of $\mathrm{PCC}$ and patient outcomes, confirms that implementation of PCC is expected to improve patient outcome by increasing patient self-care ability and improving satisfaction with care and quality of life.

A population-based survey using PPE-15: relationship of care aspects to patient satisfaction in Hong Kong. Wong EL, Leung MC, Cheung AW, Yam CH, Yeoh EK, Griffiths S, Source School of Public Health and Primary Care, the Chinese University of Hong Kong, HKSAR, Hong Kong, China. lywong@cuhk.edu.hk. ${ }^{8}$

The mean global satisfaction scores for public and private hospital care were 7.3/10 and 7.8/10, respectively. By adjusting patient demographics, the regression models show that 'want to be more involved in decision made about the care and treatment', 'respect for patient's dignity', 'patients' family have enough opportunity to talk to doctor' and 'tell about danger signals regarding illness/treatment after went home' are major determinants of the global satisfaction scores. Study concludes that communication, respect and patient engagement in provider-patient relationship are important in determining patient's satisfaction. Training and healthcare education curriculum could take this into account for ensuring the quality of PCC.

Patient experience of nursing quality in a teaching hospital in Saudi Arabia.

Al Momani M, Al Korashy H, Source Department of Nursing Administration and Education Department, King Saud University, Riyadh, Kingdom of Saudi Arabia. ${ }^{9}$

The findings of this study demonstrate negative experiences of patients with nursing care in dimensions of information, caring behavior, and nurse competency and technical care. Awareness of the importance of these dimensions of nursing care and ongoing support to investigate patients' perception periodically toward quality of nursing care are critical to success the philosophy of patient centered healthcare.
Another study done on patient satisfaction in Cyprus concludes that nurses should be made more sensitive and aware of the importance of patients' information and autonomy as well as their rights in general. Additionally, an effort should be made to improve hospitalization services and more specifically, food, where more dietary options should be given, as well as some measure taking for restricting the noise. ${ }^{10}$

Another study done to assess that factors affecting patient satisfaction in a Dental College in Tumkur City suggests that measures have to be undertaken in order to fulfill the void by placing signboards, explaining the treatment procedure/ or any delay to built a good rapport with the patient. But only targeting a reduction in complaints is not a sign of improvement. What is needed is an effective evaluation of the accessibility of procedures and proof of real action, to encourage and support complaints. ${ }^{11}$

\section{AIMS AND OBJECTIVES}

\section{Aims}

To study the level of satisfaction of in-patients at Tertiary care speciality hospital and to find out the causes for dissatisfaction.

\section{Objectives}

1. To study the level of satisfaction of in-patients in private and general wards at Tertiary care speciality hospital.

2. To find the causes for dissatisfaction, if any and suggest remedial measures.

\section{Methodology}

Study area: Tertiary care speciality hospital, cardioneuro centre, eye hospital and cancer hospital.

Study population: The study population was the inpatients from different wards including general wards and the private wards.

Sample size: A sample size of 384 has been determined at $95 \%$ confidence level with $5 \%$ precision. ${ }^{12}$

Study design: Cross-sectional descriptive study.

Duration of study: Two months (January and February, 2013).

Tool: The Northwest Territories (NWT) Hospital satisfaction questionnaire used in hospital in Fort Smith, was used as it is a valid tested tool. ${ }^{13}$

\section{Observations}

Following are the major observations:

- About $25 \%$ of the patients are from Delhi, while remaining $75 \%$ are from other states (Tables 1 and 2).

- UP, Haryana and Bihar constitutes more than $50 \%$ of the patients coming to Tertiary care speciality hospital. 
Table 1: Patient's response to the questionnaire

\begin{tabular}{|c|c|c|c|c|c|}
\hline S. no. & Service provided & Excellent & Good & Satisfactory & Poor \\
\hline 1. & How respectful was the receptionist/administration? & $21.5 \%$ & $59.1 \%$ & $19.3 \%$ & $0 \%$ \\
\hline \multirow[t]{4}{*}{2.} & How clean was the hospital? & & & & \\
\hline & Wards & $21.0 \%$ & $72.6 \%$ & $5.4 \%$ & $1.1 \%$ \\
\hline & Toilets & $8.6 \%$ & $46.2 \%$ & $40.9 \%$ & $4.3 \%$ \\
\hline & Linen & $9.4 \%$ & $60.7 \%$ & $29.6 \%$ & $0.5 \%$ \\
\hline 3. & How helpful were the signs/directions? & $19.9 \%$ & $62.4 \%$ & $16.1 \%$ & $1.6 \%$ \\
\hline 4. & How was the hospital food? & $5.4 \%$ & $57.5 \%$ & $32.3 \%$ & $4.8 \%$ \\
\hline 5. & $\begin{array}{l}\text { How were the services of medical records persons you received (time } \\
\text { taken in preparation of case file at the time of admission)? }\end{array}$ & $14.0 \%$ & $66.1 \%$ & $19.9 \%$ & $0 \%$ \\
\hline 6. & How helpful and prompt was the person sitting in billing section? & $10.7 \%$ & $64.0 \%$ & $24.2 \%$ & $1.1 \%$ \\
\hline 7. & $\begin{array}{l}\text { How helpful were the MSSO/social guides? } \\
\text { Healthcare providers } \\
\text { Nurses }\end{array}$ & $19.9 \%$ & $52.7 \%$ & $25.3 \%$ & $2.1 \%$ \\
\hline 8. & What do you think about the care you received from the nurses? & $52.1 \%$ & $38.7 \%$ & $8.6 \%$ & $0.5 \%$ \\
\hline 9. & How respectful were the nurses? & $25.8 \%$ & $63.4 \%$ & $10.7 \%$ & 0 \\
\hline 10. & $\begin{array}{l}\text { How well did the nurses answer your questions? } \\
\text { Doctors }\end{array}$ & $17.2 \%$ & $58.1 \%$ & $24.7 \%$ & 0 \\
\hline 11. & What do you think about the care you received from the doctors? & $62.4 \%$ & $33.3 \%$ & $4.3 \%$ & 0 \\
\hline 12. & How respectful were the doctors? & $20.4 \%$ & $65.6 \%$ & $14.0 \%$ & 0 \\
\hline 13. & $\begin{array}{l}\text { How well did the doctors answer your questions? } \\
\text { Paramedical services }\end{array}$ & $16.7 \%$ & $44.6 \%$ & $37.1 \%$ & $1.6 \%$ \\
\hline 14. & $\begin{array}{l}\text { What do you think about the care you received from the paramedical } \\
\text { professional (for example, the lab technologist who drew your blood, the } \\
\text { ECG Technician, Refractionist)? }\end{array}$ & $7.5 \%$ & $74.2 \%$ & $17.2 \%$ & $1.1 \%$ \\
\hline 15. & How well did the paramedical professional answer your questions? & $7.5 \%$ & $66.7 \%$ & $25.8 \%$ & $0 \%$ \\
\hline
\end{tabular}

Table 2: Patient's concurrence for treatment/procedure

\begin{tabular}{llll}
\hline S. no. & $\begin{array}{l}\text { Concurrence for treatment/ } \\
\text { procedure }\end{array}$ & Yes & No \\
\hline $1 . \quad$ & $\begin{array}{l}\text { Was your treatment/procedure } \\
\text { clearly explained to you? }\end{array}$ & $97.3 \%$ & $2.7 \%$ \\
$2 . \quad \begin{array}{l}\text { Were you involved in decisions } \\
\text { affecting your care? }\end{array}$ & $97.8 \%$ & $2.1 \%$ \\
3. $\quad \begin{array}{l}\text { Were you kept informed about } \\
\text { the care planned for you? }\end{array}$ & $97.3 \%$ & $2.7 \%$ \\
\hline
\end{tabular}

- Cancer hospital has $85 \%$ of the patients coming from outside Delhi, which reflects toward non-availability of cancer treatment facility in other parts of the country as well the quality of care being provided by cancer hospital.

Major reasons for coming to Tertiary care speciality hospital is the reputation of the Institute as well lack of facilities in local hospitals.

- More than $88 \%$ of the patients have rated the services as excellent/good.

- Less than $1 \%$ of the patients have rated the services as poor.

\section{Common Feedbacks given by Patients}

1. Better coordination among various clinical departments.

2. Improvement in the security system and installation of CCTV cameras, in various areas of the institute like emergency, outpatient department, etc.
3. Training of doctors/nurses and paramedical and other support staff in soft skill.

4. Requirement of TV/Music system in the wards.

5. Improvement in the quality of food.

6. Better maintenance and upkeep of the toilets.

\section{CONCLUSION}

1. Approximately $25 \%$ of the admitted patients are from Delhi and rest $75 \%$ are from other parts of the country (Table 3).

2. Out of the $75 \%$ more than $50 \%$ are from UP, Bihar and Haryana and other parts of the country contribute just $25 \%$ of the patients.

3. Major reasons for coming to Tertiary care speciality hospital is the reputation of the institute as well lack of facilities in local hospitals. This reflects toward the requirement of developing quality medical services in different parts of the country (Table 4).

4. The level of satisfaction among the in-patients at Tertiary care speciality hospital and various centers is quite high. More than $88 \%$ respondents have labeled the overall satisfaction as excellent/good (Table 5 and Graph 1).

5. More than $70 \%$ of the respondents have rated most of the parameters as good or excellent.

6. The two area where there is a felt requirement of improvement are:

- Cleanliness of toilets 
Table 3: Demographic distribution of the patients

\begin{tabular}{lllllll}
\hline Hospital area & Delhi & Haryana & Uttar Pradesh & Bihar & Rajasthan & Others \\
\hline Main hospital & $30 \%$ & $13.5 \%$ & $26.5 \%$ & $11.9 \%$ & $5 \%$ & $12.7 \%$ \\
Cardioneuro centre & $21.1 \%$ & $17.8 \%$ & $31.1 \%$ & $15.6 \%$ & $4.4 \%$ & $10.0 \%$ \\
Eye hospital & $33.3 \%$ & $11.8 \%$ & $24.7 \%$ & $15.1 \%$ & $5.9 \%$ & $8.6 \%$ \\
Cancer hospital & $15 \%$ & $10 \%$ & $30 \%$ & $5.5 \%$ & $4.5 \%$ & $35 \%$ \\
Average & $25 \%$ & $13.3 \%$ & $28.1 \%$ & $12 \%$ & $5 \%$ & $16.6 \%$ \\
\hline
\end{tabular}

Table 4: Reason for coming to Tertiary Care Speciality Hospital

\begin{tabular}{lllll}
\hline Hospital area & $\begin{array}{l}\text { Lack of availability of } \\
\text { facility in local hospital }\end{array}$ & $\begin{array}{l}\text { Unable to afford } \\
\text { treatment in local } \\
\text { hospital }\end{array}$ & $\begin{array}{l}\text { Reputation of Tertiary } \\
\text { Care Speciality Hospital }\end{array}$ & Any other \\
\hline Main hospital & $33.46 \%$ & $10.76 \%$ & $48.84 \%$ & $6.92 \%$ \\
Cardioneuro centre & $32 \%$ & $16.66 \%$ & $34 \%$ & $9 \%$ \\
Eye hospital & $50.54 \%$ & $46.24 \%$ & $69.35 \%$ & $7.53 \%$ \\
Cancer hospital $^{*}$ & $35 \%$ & $17.5 \%$ & $40 \%$ & $7.5 \%$ \\
\hline
\end{tabular}

${ }^{*}$ Cumulative percentage is more than $100 \%$ as patients have more than one reason for coming to Tertiary Care Speciality Hospital

Table 5: Overall level of satisfaction

\begin{tabular}{lllll}
\hline Hospital area & Excellent & Good & Satisfactory & Poor \\
\hline Main hospital & $26.92 \%$ & $59.23 \%$ & $13 \%$ & $0.84 \%$ \\
Cardioneuro centre & $8.9 \%$ & $76.7 \%$ & $14 \%$ & $0.4 \%$ \\
Eye hospital & $13.4 \%$ & $78.49 \%$ & $7.53 \%$ & $0.54 \%$ \\
Cancer hospital & $20 \%$ & $70 \%$ & $9.5 \%$ & $0.5 \%$ \\
Average & $17.3 \%$ & $71.1 \%$ & $10.9 \%$ & $0.7 \%$ \\
\hline
\end{tabular}

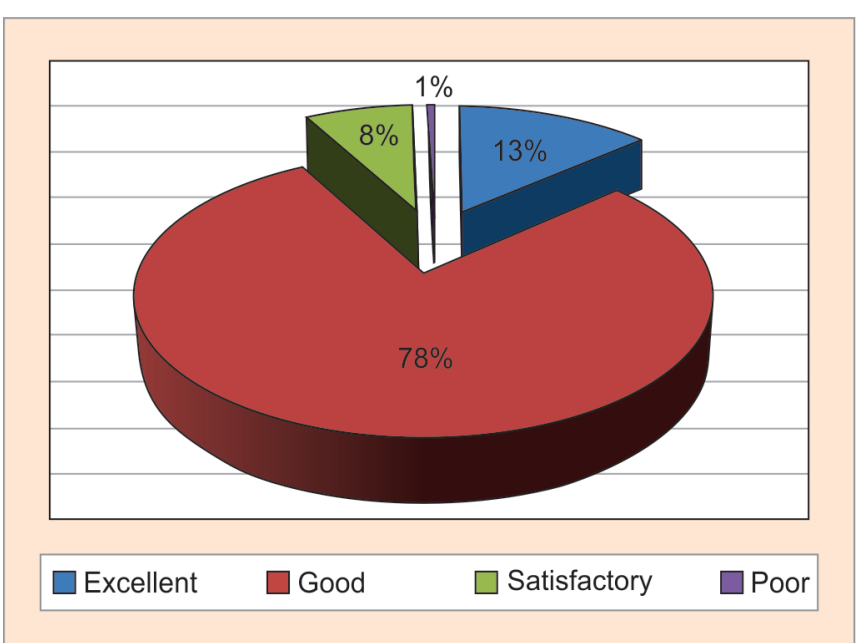

Graph 1: Overall level of satisfaction

- Dietary services

7. Medical care: Doctors-Approximately $95 \%$ of the respondents have labeled the care given by doctors as excellent/good and $85 \%$ have labeled that the doctors were respectful (excellent/good). While on the contrary $61 \%$ of the patients have labeled the responses of doctors as excellent/good for the queries of the patients, and remaining $39 \%$ have labeled it as satisfactory or poor. Similarly 24.73 and $25.81 \%$ of respondents have labeled the response as satisfactory or poor for nurses and paramedics respectively. These findings are in consonance

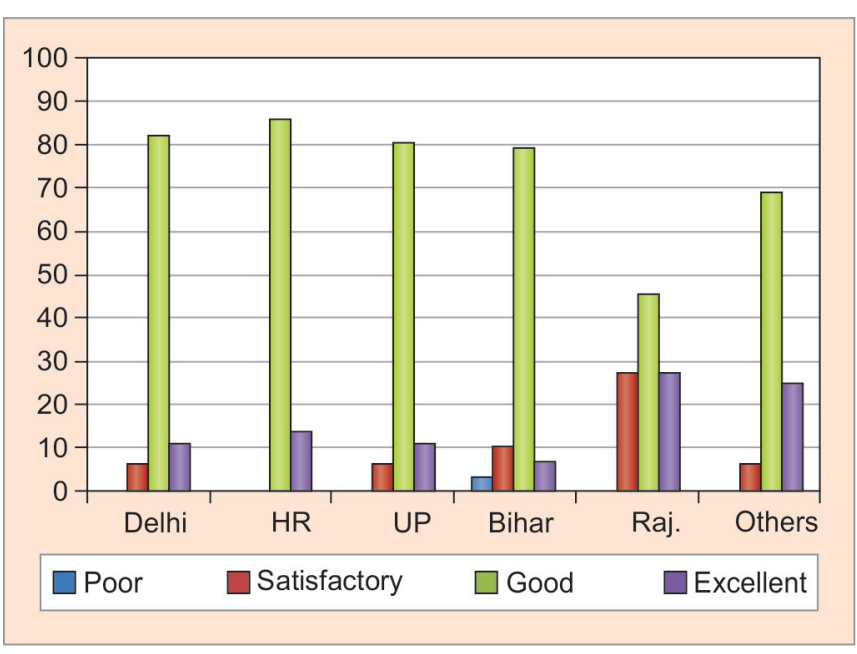

Graph 2: Level of satisfaction among patients from different states

with the findings of the study A population-based survey using PPE-15: relationship of care aspects to patient satisfaction in Hong Kong Wong EL, et al (Table 1).

Patient satisfaction is an indicator of how the patient has perceived the other qualitative aspects of care and can be used as a proxy measure of those aspects. The study concludes that the overall level of satisfaction at Tertiary care speciality hospital and various Centres is quite high and encouraging, but there is always a scope of improvement. The level of satisfaction among patients from different states is quite high and almost same (Graph 2). 


\section{REFERENCES}

1. WHO. World Health Organization, Technical Report Series 706. 1984.

2. Donabedian A. The definition of quality and approaches to its assessment. Ann Arbor, Michigan: Health Administration Press 1980.

3. Demir CCY. Determinants of patient satisfaction in a military teaching hospital. J Health Quality 2002;24(2):30-34.

4. Institute of Health Management Research.

5. KGN. Customer Satisfaction in Hospitals. Indian Express 2001.

6. Kodali RR, Ramacharyulu P. A cross-sectional study of satisfaction of in-patients in a private medical college in AP Indian J Med Science [Internet]. 2011. Available at: file:///c:/users/dell/ desktop/thesis wor ppt final/pat sat/pat sat survey ROL/A cross sectional study of satisfaction of ... [Indian J Med Sci. 2011] PubMed - NCBI.htm.

7. Poochikian-Sarkissian S, Sidanis F-PM. Examining the relationship between patient centered care and outcomes. Can J Neurosci Nurs. [Internet]. 2010. Available at: file://c:/users/dell/desktop/ thesis wor ppt final/pat sat/pat sat survey ROL/Examining the relationship between patie... [Can J Neurosci Nurs. 2010] - PubMed - NCBI.htm.

8. Wong EL, Leung MC, Cheung AW YC. A population-based survey using PPE-15: relationship of care aspect to patient satis- faction in Hong Kong. Int J Qual Health Care. [Internet]. 2011. Available at: file://c:/users/dell/desktop/thesis wor ppt final/pat sat/pat sat survey ROL/A population-based survey using PPE-1... [Int J Qual Health Care. 2011] - PubMed - NCBI.htm.

9. Momani MAKH. Patient experience of nursing quality in a teaching hospital in Saudi Arabia. Iran J Public Health [Internet]. 2012. Available at: file:///c:/users/dell/desktop/thesis wor ppt final/pat sat/pat sat survey ROL/Patient experience of nursing quality i... [Iran J Public Health. 2012] - PubMed NCBI.htm.

10. Merkouris A, Andreadou A, Athini E, Hatzimbalasi M, Papastavrou E, Dean A, et al. Assessment of patient satisfaction in public hospitals in Cyprus: a descriptive study. Health Science Journal 2013;7(1):28-40.

11. Kashinath KR, Bharateesh JV, Agali C. Factors affecting patient satisfaction among those attending an Outpatient Department of a Dental College in Tumkur City - a survey. J Dent Sci Research 2010;1(2):1-10.

12. Jawaha SK. A study on out patient satisfaction at a Superspecialty Hospital in India [Internet]. Internet Journal of Medical Update - Ejournal. 2007.p. 1. Available at: http://www.ajol.info/ index.php/ijmu/article/view/39849.

13. Smith F. Northwest Territories Hospital satisfaction questionnaire; 2005. p. 1-14. 